\title{
THE USE OF TECHNETIUM TC 99M ANNEXIN V FOR IN VIVO IMAGING OF APOPTOSIS DURING CARDIAC ALLOGRAFT REJECTION
}

Patrick W. Vriens, MD

Francis G. Blankenberg, $\mathrm{MD}^{\mathrm{b}}$

Jan H. Stoot ${ }^{\mathrm{a}}$

Katsuichi Ohtsuki, MD ${ }^{\mathrm{b}}$

Gerald J. Berry, MD ${ }^{c}$

Jonathan F. Tait, $\mathrm{MD}^{\mathrm{d}}$

H. William Strauss, MD $^{\mathrm{b}}$

Robert C. Robbins, MD
Objective: Apoptosis, or programmed cell death, has been suggested as a mechanism of immunologic injury during cardiac allograft rejection. We tested the hypothesis that technetium Tc 99m annexin V, a novel radiopharmaceutical used to detect apoptosis, can be used to detect cardiac allograft rejection by nuclear imaging. Methods: Untreated ACI rats served as recipients of allogeneic PVG rat $(n=66)$ or syngeneic ACI rat ( $n=30)$ cardiac grafts. Untreated recipient animals underwent ${ }^{99}$ Tc-annexin $\mathrm{V}$ imaging daily for 7 days. Region of interest analysis was used to quantify the uptake of ${ }^{99} \mathrm{~m}$ Tc-annexin V. Immediately after imaging grafts were procured for histopathologic analysis and terminal deoxynucleotidyltransferase-mediated deoxyuridine triphosphatebiotin nick-end labeling of apoptotic nuclei. One group was treated with $10 \mathrm{mg} / \mathrm{kg} / \mathrm{d}$ cyclosporine (INN: ciclosporin) commencing on day 4 after transplantation $(n=6)$. Results: Untreated allografts showed histologic signs of rejection 4 days after transplantation. Apoptotic nuclei could be demonstrated in myocytes, endothelial cells, and graft-infiltrating cells of all rejecting allografts. Nuclear imaging revealed a significantly greater uptake of ${ }^{99} \mathrm{~m}$ Tc-annexin $\mathrm{V}$ in rejecting allogeneic grafts than in syngeneic grafts on day $4(P=.05)$, day $5(P<.001)$, day $6(P<.001)$, and day $7(P=.013)$ after transplantation. A correlation between the histologic grade of acute rejection and uptake of ${ }^{99 m} \mathrm{Tc}-$ annexin $\mathrm{V}$ was observed $\left(r^{2}=0.87\right)$. After treatment of rejection with cyclosporine, no apoptotic nuclei could be identified in allografts and uptake of ${ }^{99}$ Tc-annexin V decreased to baseline. Conclusions: Apoptosis occurs during acute cardiac allograft rejection and disappears after treatment of rejection. ${ }^{99 m} \mathrm{Tc}-$ annexin $\mathrm{V}$ can be used to detect and monitor cardiac allograft rejection. (J Thorac Cardiovasc Surg 1998;116:844-53)
From the Department of Cardiothoracic Surgery, ${ }^{\mathrm{a}}$ the Division of Nuclear Medicine, Department of Radiology, ${ }^{\mathrm{b}}$ and the Department of Pathology, ${ }^{\mathrm{c}}$ Stanford University Medical Center, Stanford, Calif, and the Department of Laboratory Medicine, ${ }^{\mathrm{d}}$ University of Washington, Seattle, Wash.

Supported by the Ralph and Marian Falk Foundation for Cardiovascular Research, the National Institutes of Health grant HL-47151, Child Health Research Fund from Lucile Salter Packard Children's Hospital at Stanford, and funds from the Division of Nuclear Medicine, Department of Radiology, Stanford. P. W. Vriens is supported by the Ter Meulen Fund of the Royal Dutch Academy of Sciences and Arts, and the Professor Michaël van Vloten Fund. J. H. Stoot is supported by the Dutch Heart Association.

Read at the Seventy-eighth Annual Meeting of The American Association for Thoracic Surgery, Boston, Mass, May 3-6, 1998.

Received for publication May 8, 1998; revisions requested May 28, 1998; revisions received July 7, 1998; accepted for publication July 10, 1998.

Address for reprints: Robert C. Robbins, MD, Department of Cardiothoracic Surgery, Stanford University Medical Center, Stanford, CA 94305-5407.

Copyright $\odot 1998$ by Mosby, Inc.

$0022-5223 / 98 \$ 5.00+0 \quad \mathbf{1 2 / 6 / 9 3 0 9 2}$
A cute rejection remains a limiting factor in the success of cardiac allotransplantation. Host sensitized lymphocytes play a major role, damaging donor heart myocytes by infiltrating the graft and causing cell death. ${ }^{1}$ Two different mechanisms of immunologic injury have been suggested: necrosis (unregulated cell death) and apoptosis (programmed cell death). By inducing apoptosis, $\mathrm{T}$ cells can cause lysis of target cells. $^{2}$ Recent studies have indicated apoptosis as an important mechanism of cell death during rejection of renal, ${ }^{3}$ hepatic, ${ }^{4}$ and small-intestinal allografts. ${ }^{5}$ The role of apoptosis in rejection of cardiac allografts is unclear. ${ }^{6-9}$ Apoptosis has been shown to occur during cardiac allograft rejection, ${ }^{7,8}$ and the presence of apoptotic myocytes in endomyocardial biopsy specimens correlates with the histologic grade of rejection. ${ }^{7}$

One of the earliest cellular features of apoptotic cell death is loss of the normal asymmetry of the cytoplasm cell membrane. ${ }^{10}$ Phosphatidylserine is a phospholipid 
that is normally restricted to the inner leaflet of the lipid bilayer. ${ }^{11}$ When a cell is committed to programmed cell death, phosphatidylserine is expressed on the surface. ${ }^{12}$ The externalization of phosphatidylserine occurs before the terminal apoptotic changes of membrane bleb formation, condensation of the cytoplasmic matrix and organelles, condensation of chromatin, and cleavage of chromatin by endonucleases. ${ }^{13}$ Currently, apoptosis can be demonstrated in histologic sections with in situ staining of these DNA breaks by terminal deoxynucleotidyltransferase-mediated deoxyuridine triphosphate-biotin nick-end labeling imaging (TUNEL). ${ }^{14}$

Fluorescein-labeled annexin $\mathrm{V}$ has been employed to detect apoptotic cells in vitro by flow cytometry. ${ }^{15}$ Annexin V is a human protein of 319 amino acids with a molecular weight of $36 \mathrm{kd}$ and affinity for membranebound phosphatidylserine, both in vitro and in vivo (dissociation constant $7 \mathrm{nmol} / \mathrm{L}){ }^{15}$ Recently a novel technique has been developed to label annexin $\mathrm{V}$ with technetium Tc 99m. ${ }^{16}$ Hydrazinonicotinamide (HYNIC), a bifunctional molecule that binds to proteins and conjugates ${ }^{99 \mathrm{~m}} \mathrm{Tc}$, was used to create a derivative of annexin $\mathrm{V}$ before radiolabeling with ${ }^{99 \mathrm{~m}} \mathrm{Tc} .{ }^{17}$

The purpose of this study was to test the hypothesis that apoptosis is an important mechanism for cardiac allograft rejection and that technetium Tc 99m annexin $\mathrm{V}$ can be used to detect apoptosis during rejection in vivo by nuclear imaging. Furthermore, it was hypothesized that ${ }^{99 \mathrm{~m}} \mathrm{Tc}$-annexin $\mathrm{V}$ imaging could be used to monitor immunologically mediated myocyte damage and cardiac allograft rejection. Histologic signs of rejection were correlated with the uptake of ${ }^{99 \mathrm{~m}} \mathrm{Tc}-$ annexin $\mathrm{V}$ by the transplanted heart. Finally, the successful treatment of rejection with cyclosporine (INN: ciclosporin) and corticosteroids was correlated with the uptake of ${ }^{99 \mathrm{~m}} \mathrm{Tc}$-annexin $\mathrm{V}$.

\footnotetext{
Methods

Animals. Young adult, pathogen free, male ACI (RT1a) and PVG (RT1c) rats weighing between 200 and $250 \mathrm{~g}$ were used in this study (Harlan Sprague Dawley, Indianapolis, Ind). Animals were maintained at the animal care facilities of the Department of Cardiothoracic Surgery, Stanford University Medical Center, Stanford, Calif, under standard temperature, humidity, and time-regulated light conditions. Water and food were provided ad libitum. Animals were treated in a humane manner, conforming to the "Principles of Laboratory Animal Care" formulated by the National Society for Medical Research and the "Guide for the Care and Use of Laboratory Animals" prepared by the National Academy of Sciences and published by the National Institutes of Health (NIH publication No. 86-23, revised 1985). ACI rats served as recipients of cardiac grafts from allogeneic PVG donor rats or syngeneic ACI donor rats.
}

Anesthesia. Before transplantation or nuclear imaging, animals were anesthetized by inhalation of methoxyflurane (1\%-2\%) followed by an intraperitoneal injection of pentobarbital $(40 \mathrm{mg} / \mathrm{kg})$. Heart rate, ventilation rate, and temperature were closely monitored during anesthesia. Rats were briefly anesthetized with methoxyflurane to facilitate the administration of medication or the assessment of the graft.

Heart transplantation. Donor cardiac grafts were transplanted heterotopically into the abdomens of recipient rats according to a modification of the technique described by Ono and Lindsey. ${ }^{18}$ Native hearts were harvested from donor animals after treatment with heparin. Donor hearts were perfused with Stanford cardioplegia solution and stored in cold saline solution $\left(0^{\circ}-4^{\circ} \mathrm{C}\right)$. End-to-side anastomoses were made from the ascending aorta of the donor heart to the abdominal aorta of the recipient and from the donor pulmonary artery to the recipient vena cava after ligation of the venae cavae and pulmonary veins of the donor heart. Ischemic times ranged between 20 and 30 minutes. Cardiac allograft function was assessed by daily palpation in 1 control group $(n=6)$. Rejection was deemed complete when palpable ventricular contractions ceased.

Radiolabeling of annexin V. Human annexin V was produced by expression in Escherichia coli and purified as previously described elsewhere. ${ }^{19}$ Annexin V was treated with HYNIC to form a derivative and then bound to ${ }^{99 \mathrm{~m}} \mathrm{Tc}$ according to the methods described by Blankenberg and colleagues. ${ }^{20}$ The specific activity of the ${ }^{99 \mathrm{~m}} \mathrm{Tc}-\mathrm{HYNIC}$-annexin $\mathrm{V}$ was between 100 and $200 \mu \mathrm{Ci} / \mu \mathrm{g}$ protein. Radiologic purity was $>97 \%$, as determined by instant thin-layer chromatography.

Nuclear imaging. Untreated recipient animals with allogeneic cardiac grafts (group $\mathrm{I}, \mathrm{n}=43$ ) and recipient animals with syngeneic cardiac grafts (group II, $\mathrm{n}=23$ ) underwent nuclear imaging with ${ }^{99 \mathrm{~m}} \mathrm{Tc}$-annexin $\mathrm{V}$ daily for 7 days after transplantation. Animals within groups I and II were killed immediately after nuclear imaging and on various days after transplantation, and grafts were procured for histologic and TUNEL analysis. Animals were injected through the tail vein with $1.0 \mathrm{mCi}{ }^{99 \mathrm{~m}} \mathrm{Tc}-\mathrm{HYNIC}$-annexin $\mathrm{V} 1$ hour before imaging. Recipient rats were anesthetized and placed in the prone position on a table, and planar imaging was performed in the anterior projection with a mobile Ohio scintillation camera (Technicare, Solon, Ohio) with a high-resolution parallelhole collimator. A $20 \%$ window was centered on the $140 \mathrm{keV}$ photopeak of ${ }^{99 \mathrm{~m}} \mathrm{Tc}$, and the nuclear image was recorded into a $256 \times 256$ matrix of a computer for digital display and analysis of the image (ICON; Siemens, Hoffman Estates, Ill). All images were recorded for 10 minutes. Region of interest analysis was performed to calculate the uptake of ${ }^{99} \mathrm{~m} \mathrm{Tc}-$ annexin $\mathrm{V}$ in the transplanted heart. Uptake was expressed in counts in the region of interest as a percentage of total body counts.

Immunosuppression. One cohort of animals was treated with cyclosporine, commencing 4 days after transplantation (group III, n =6). Cyclosporine (Sandoz, Basel, Switzerland) was dissolved in olive oil and administered orally by gavage at a dose of $10 \mathrm{mg} / \mathrm{kg} / \mathrm{d}$. One cohort was treated with cyclosporine and methylprednisolone commencing 4 days 

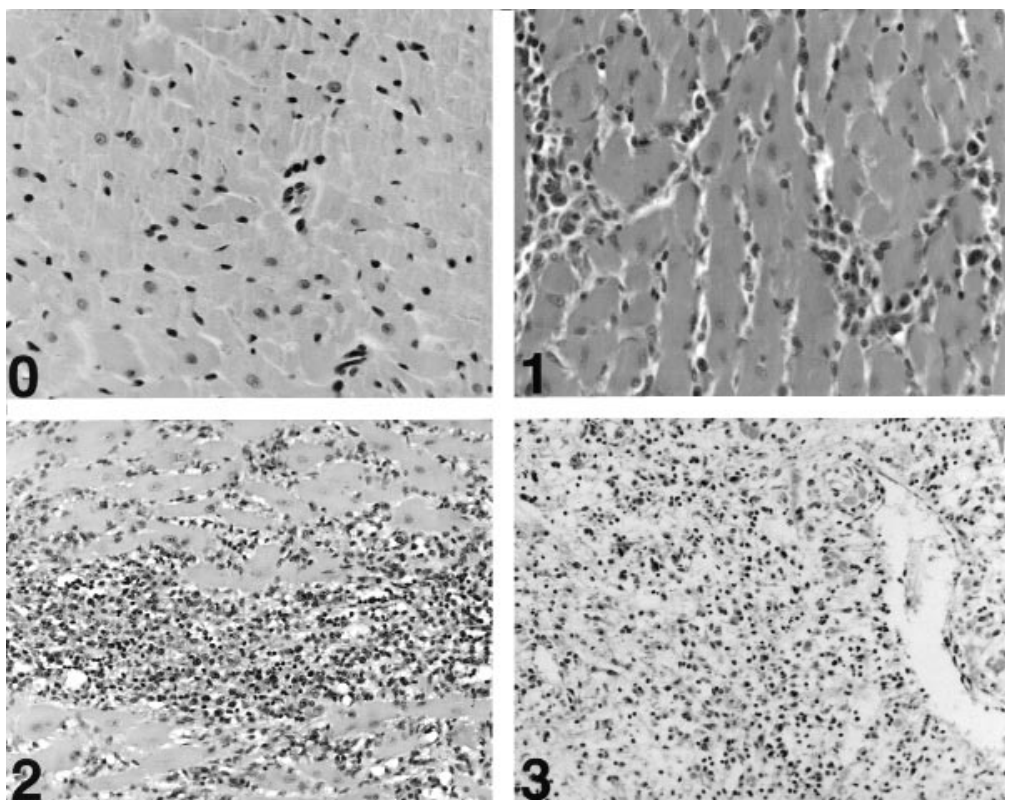

Fig 1. Histologic grading of acute rejection in rats. Top left: Grade 0, no rejection (hematoxylin and eosin stain; original magnification $\times 400$ ). Top right: Grade 1 , mild rejection-sparse, focal or diffuse mononuclear cell infiltrate with no myocyte damage (hematoxylin and eosin stain; original magnification $\times 400$ ). Bottom left: Grade 2, moderate rejection - focal or multifocal mononuclear cell infiltrate and myocyte damage (hematoxylin and eosin stain; original magnification $\times 400)$. Bottom right: Grade 3, severe rejection-diffuse mononuclear cell infiltrate and conspicuous myocyte damage (hematoxylin and eosin stain; original magnification $\times 200$ ).

after transplantation (group IV, $\mathrm{n}=6$ ). Methylprednisolone was dissolved in saline solution and administered intraperitoneally at a dose of $50 \mathrm{mg} / \mathrm{kg}$ on day $4,25 \mathrm{mg} / \mathrm{kg} / \mathrm{d}$ on days 5 and 6 , and $10 \mathrm{mg} / \mathrm{kg} / \mathrm{d}$ for the rest of the study period. Groups III and IV underwent nuclear imaging on days 4, 11, and 18 after transplantation and were killed after imaging on day 18.

Histopathologic studies. Animals were killed after nuclear imaging. Samples of the procured transplanted hearts were fixed in a $10 \%$ buffered formalin solution and subsequently embedded in paraffin. Paraffin sections of $5 \mu \mathrm{m}$ were stained with hematoxylin and eosin to assess histopathologic changes. Sections were evaluated by 2 separate investigators in a blinded fashion. Acute rejection was scored in a semiquantitive manner $(0$, no rejection; 1 , mild rejection, sparse, focal or diffuse mononuclear cell infiltrate with no myocyte damage; 2, moderate rejection, focal or multifocal mononuclear cell infiltrate and myocyte damage; or 3, severe rejection, diffuse mononuclear cell infiltrate and conspicuous myocyte damage; Fig 1).

TUNEL staining. Nuclear DNA fragmentation was analyzed by C-terminal TUNEL to assess for apoptosis in $5 \mu \mathrm{m}$ paraffin sections with a commercially available peroxidase kit (Apoptag; Oncor, Gaithersburg, Md). Sections were evaluated by 2 separate investigators in a blinded fashion. Presence of TUNEL-reactive nuclei was assessed for in infiltrating cells, endothelial cells, and myocytes of cardiac grafts. At least 20 fields were analyzed at $\times 400$ magnification $(0$, none; + , scattered; or ++ , many or multifocal distribution). Small bowels and testes of untreated PVG rats were used as positive control preparations. Native hearts of untreated PVG rats were used as negative control preparations.

Statistical analysis. Values are given as mean \pm standard deviation. Differences between groups were analyzed with a 2-tailed Student $t$ test with unequal variance. A 2-tailed paired Student $t$ test was used to analyze sequential results as appropriate. Correlation between values was calculated as the squared Pearson product moment correlation coefficient $\left(r^{2}\right)$.

\section{Results}

Histopathologic examination. Rejection of PVG allografts by untreated ACI recipients (control group) was complete after $7.5 \pm 0.5$ days, as indicated by absence of palpable ventricular contractions. Such histologic signs of rejection as infiltration of mononuclear cells, however, were clearly present at day 4 in PVG allografts (group I). The mean histologic grades of acute rejection on each day after transplantation are listed in Table I. There was an increase in the grade of acute rejection each day after transplantation $\left(r^{2}=\right.$ 0.91 ; Fig 2). No signs of rejection were detected in syngeneic ACI grafts (group II).

TUNEL studies. TUNEL images of cardiac allografts with histologic signs of acute rejection all 


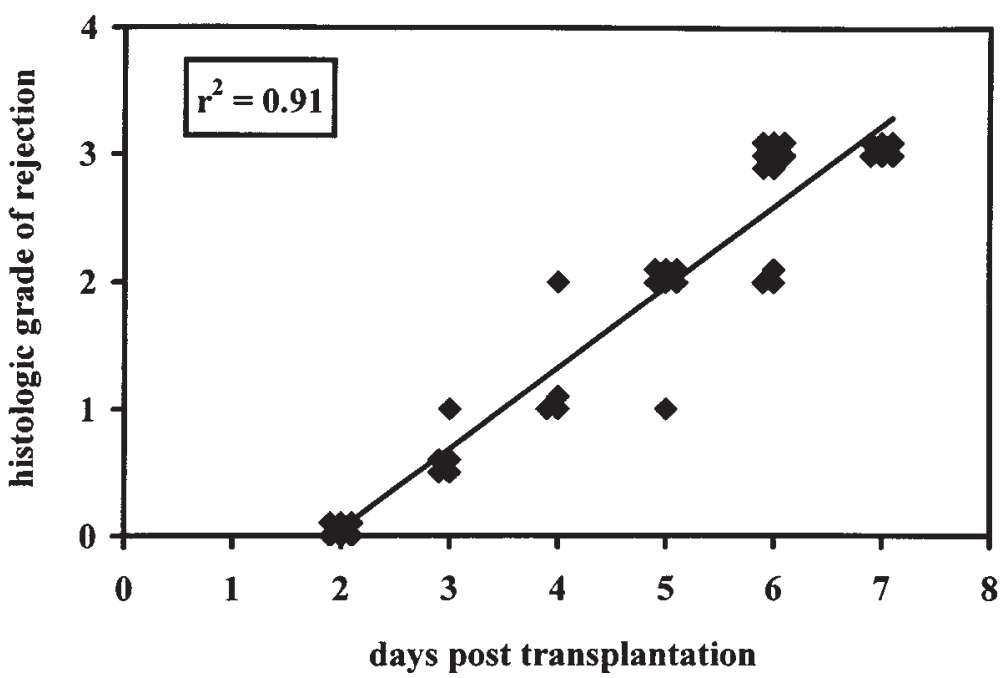

Fig 2. Correlation between time after transplantation and histologic grade of acute rejection of heterotopic PVG allografts in untreated ACI rats. Histologic grades are as shown in Fig 1. Rejection was complete after $7.5 \pm 0.5$ days, as indicated by absence of palpable ventricular contractions.

showed scattered apoptotic nuclei in graft-infiltrating inflammatory cells, endothelial cells, and myocytes. Apoptotic cells were absent in cardiac grafts that did not show histologic signs of acute rejection. Specimens with grade 2 rejection showed many apoptotic nuclei in inflammatory cells, whereas specimens with grade 3 rejection showed apoptotic nuclei predominantly in the myocytes (Table II, Fig 3).

Nuclear imaging. Uptake of ${ }^{99 \mathrm{~m}} \mathrm{Tc}$-annexin V was readily visible on nuclear image of the heterotopically placed PVG allografts in untreated animals (group I) on days 4, 5, 6, and 7 after transplantation. Syngeneic ACI grafts (group II) did not show any detectable uptake of ${ }^{99 \mathrm{~m}} \mathrm{Tc}$-annexin V (Fig 4). Uptake of the radiopharmaceutical by syngeneic grafts did not differ from uptake by the native heart, as confirmed by scintillation well counting (data not shown).

Uptake of ${ }^{99 \mathrm{~m}} \mathrm{Tc}$-annexin $\mathrm{V}$ by transplanted allografts (group I), measured as a percentage of whole-body uptake, was not different from that in syngeneic control animals (group II) on days 1 (allogeneic [n $=5$ ] vs syngeneic [n $=3], 42 \% \pm 14 \%$ vs $41 \% \pm 10 \% ; P=.72), 2$ (allogeneic $[\mathrm{n}=6]$ vs syngeneic $[\mathrm{n}=3], 43 \% \pm 17 \%$ vs $42 \% \pm 13 \% ; P=.95$ ), and 3 (allogeneic [n $=5]$ vs syngeneic $[\mathrm{n}=5], 39 \% \pm 6 \%$ vs $35 \% \pm 12 \% ; P=.50$ ). However, uptake of ${ }^{99 \mathrm{~m}} \mathrm{Tc}$-annexin $\mathrm{V}$ by transplanted allografts (group I) was significantly greater than in syngeneic control animals (group II) on days 4 (allogeneic $[\mathrm{n}=4]$ vs syngeneic $[\mathrm{n}=3], 125 \% \pm 44 \%$ vs $58 \% \pm 34 \% ; P=.05$ ), 5 (allogeneic $[\mathrm{n}=5]$ vs syn-
Table I. Histologic grade of rejection of allogeneic $P V G$ grafts and syngeneic ACI grafts after transplantation to untreated $A C I$ recipient rats

\begin{tabular}{lccccc} 
& \multicolumn{2}{c}{$\begin{array}{l}\text { Allogeneic }(N=43) \\
\text { trans after }\end{array}$} & & \multicolumn{2}{c}{ Syngeneic $(N=23)$} \\
\cline { 2 - 3 } \cline { 5 - 6 } trantation & Grade & $n$ & & Grade & $n$ \\
\hline Day 1 & $0.0 \pm 0.0$ & 5 & & $0.0 \pm 0.0$ & 3 \\
Day 2 & $0.0 \pm 0.0$ & 6 & & $0.0 \pm 0.0$ & 3 \\
Day 3 & $0.6 \pm 0.2$ & 5 & & $0.0 \pm 0.0$ & 5 \\
Day 4 & $1.3 \pm 0.5$ & 4 & & $0.0 \pm 0.0$ & 3 \\
Day 5 & $1.9 \pm 0.4$ & 7 & & $0.0 \pm 0.0$ & 3 \\
Day 6 & $2.3 \pm 0.5$ & 11 & & $0.0 \pm 0.0$ & 3 \\
Day 7 & $3.0 \pm 0.0$ & 6 & & $0.0 \pm 0.0$ & 3 \\
\hline
\end{tabular}

Histologic grades, given as mean \pm standard deviation, are as shown in Fig 1 .

geneic $[\mathrm{n}=3], 140 \% \pm 53 \%$ vs $40 \% \pm 18 \% ; P<.001)$, 6 (allogeneic [n=11] vs syngeneic [n $=3], 234 \% \pm$ $46 \%$ vs $46 \% \pm 5 \% ; P<.001$ ), and 7 (allogeneic $[\mathrm{n}=6]$ vs syngeneic $[\mathrm{n}=3], 196 \% \pm 15 \%$ vs $40 \% \pm 16 \% ; P=$ .013 ; Fig 5). No toxic effects of intravenous injection of ${ }^{99 \mathrm{~m}} \mathrm{Tc}-$ annexin $\mathrm{V}$ were noted.

Correlation between histopathologic examination and nuclear imaging. After histopathologic examination and nuclear imaging, the data were further analyzed according to histologic grade of acute rejection. Transplanted grafts that showed the same histologic grade of rejection had similar percentages of uptake of ${ }^{99 \mathrm{~m}} \mathrm{Tc}-$ annexin $\mathrm{V}$. The differences in uptake of ${ }^{99 \mathrm{~m}} \mathrm{Tc}-$ annexin $\mathrm{V}$ between groups were statistically sig- 


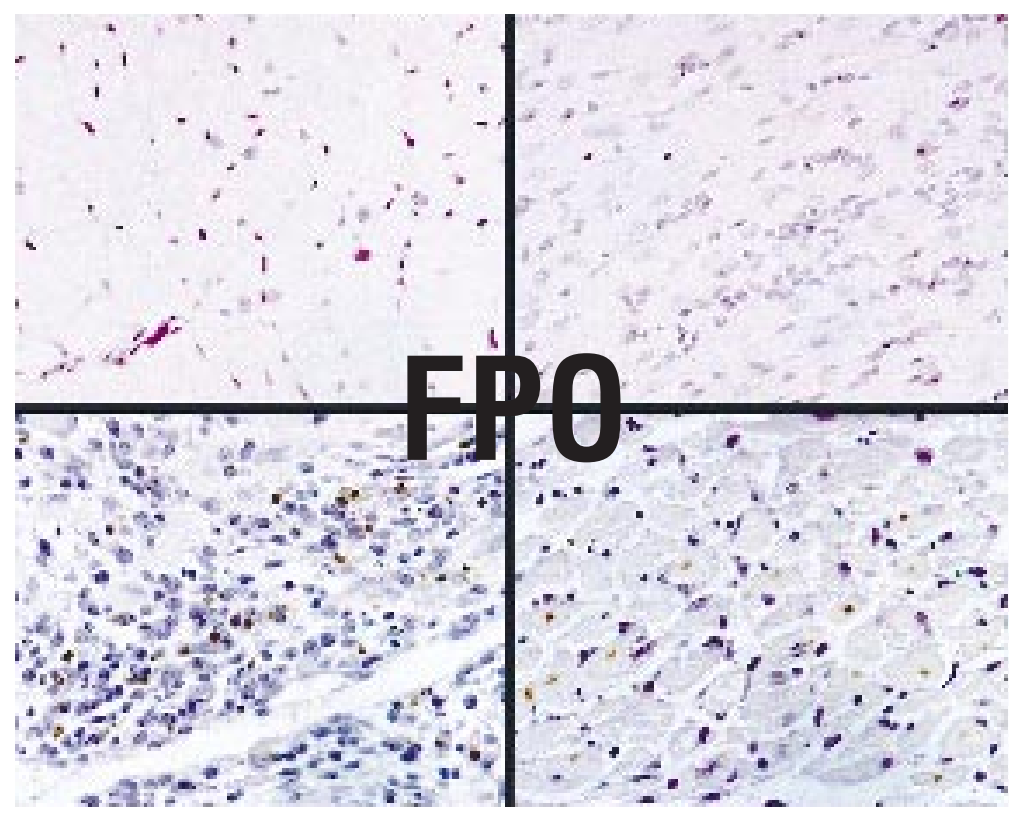

Fig 3. TUNEL staining in representative cardiac grafts. Top left: Absence of apoptosis in a graft that did not show histologic signs of acute rejection (original magnification, $\times 400$ ). Top right: Absence of apoptosis in a graft after recovery from rejection, after 14 days of treatment with cyclosporine (original magnification $\times 400$ ). Bottom left: Apoptotic nuclei of inflammatory cells in a graft with grade 2 rejection (original magnification $\times 400$ ). Bottom right: Apoptotic nuclei of myocytes in a graft with grade 3 rejection (original magnification $\times 400$ ).
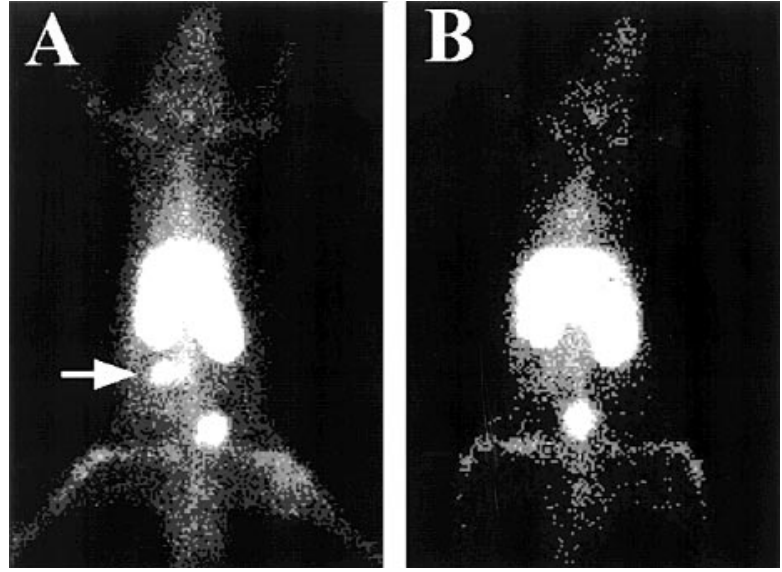

Fig 4. Uptake of ${ }^{99 \mathrm{~m}} \mathrm{Tc}-$ annexin $\mathrm{V}$ on day 4 after transplantation in untreated ACI recipients in an allogeneic graft (arrow, $\mathbf{A}$, group I) and a syngeneic graft (B, group II). Panels show representative images on day 4 after transplantation.

nificant (Table III). A linear correlation between the histologic grade of acute rejection and the percentage of uptake of ${ }^{99 \mathrm{~m}} \mathrm{Tc}-$ annexin $\mathrm{V}$ was observed $\left(r^{2}=0.87\right.$; Fig 6).

Correlation between treatment of rejection and nuclear imaging. Treatment of ACI recipients of PVG
Table II. TUNEL: Presence of apoptotic nuclei in specimens of cardiac grafts with the same histologic grade of acute rejection (groups I and II), and of cardiac grafts that had recovered from rejection after treatment with immunosuppressive therapy (group III and IV)

\begin{tabular}{lccc}
\hline Rejection $*$ & $\begin{array}{c}\text { Inflammatory } \\
\text { cellst }\end{array}$ & $\begin{array}{c}\text { Endothelial } \\
\text { cellst }\end{array}$ & Myocytes ${ }^{\dagger}$ \\
\hline Grade 0 $(\mathrm{n}=31)$ & 0 & 0 & 0 \\
Grade $1(\mathrm{n}=5)$ & + & + & + \\
Grade 2 $(\mathrm{n}=10)$ & ++ & + & + \\
Grade 3 $(\mathrm{n}=14)$ & + & + & ++ \\
Recovery $(\mathrm{n}=12)$ & $0 /+$ & 0 & 0
\end{tabular}

Data are from 20 fields, $400 \times$ magnification.

* Grafts that showed grade 0.5 rejection are not included in this table $(n=6)$.

allografts starting on day 4 after transplantation with cyclosporine alone (group III) or cyclosporine and methylprednisolone (group IV) successfully reversed rejection. All allografts recovered from rejection, as indicated by maintenance of a strong, palpable heartbeat until day 18 , when animals were killed. Histopathologic analysis confirmed resolution of rejection in both groups. Occasional sections demonstrated sparse mononuclear cell infiltration; however, no evidence of 


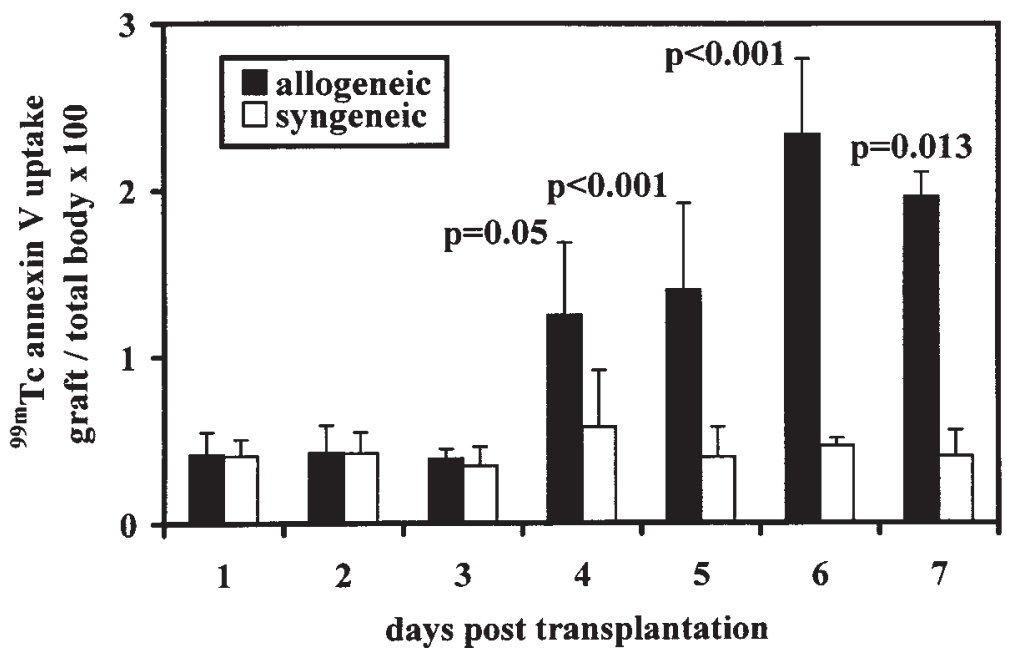

Fig 5. Uptake of ${ }^{99 \mathrm{~m}} \mathrm{Tc}-$ annexin $\mathrm{V}$, measured as a percentage of total body uptake, in rejecting allogeneic PVG grafts (group I, filled bars), and nonrejecting syngeneic ACI grafts (group II, open bars), on days 1 through 7 after transplantation in untreated ACI recipients. Uptakes in grafts from groups I and II were compared on each day by a 2-tailed unpaired Student $t$ test with unequal variance.

myocyte damage was observed. TUNEL images of allografts that had been treated with cyclosporine with or without methylprednisolone and had recovered from rejection showed no signs of apoptosis in myocytes or endothelial cells and only showed extremely occasional apoptotic nuclei in inflammatory cells after 14 days of treatment (Table II, Fig 3).

Uptake of ${ }^{99 \mathrm{~m}} \mathrm{Tc}$-annexin $\mathrm{V}$ by transplanted allografts in group III on day 4 after transplantation significantly increased from that on day 1 (day 4 vs day $1,1.53 \pm$ 0.68 vs $42 \% \pm 14 \%, P=.001$ ). Uptake of ${ }^{99 \mathrm{~m}} \mathrm{Tc}-$ annexin $\mathrm{V}$ decreased significantly on day 11 after transplantation, after 7 days of treatment with cyclosporine (day 11 vs day $4,76 \% \pm 37 \%$ vs $153 \% \pm 68 \%, P=.042$ ). Uptake of ${ }^{99 \mathrm{~m}} \mathrm{Tc}$-annexin $\mathrm{V}$ decreased even further on day 18 after transplantation, after 14 days of treatment, to a value comparable with that seen on day 1 after transplantation (day 18 vs day $4,34 \% \pm 13 \%$ vs $153 \%$ $\pm 68 \%, P=.007$; day 18 vs day $1,34 \% \pm 13 \%$ vs $42 \%$ $\pm 14 \% ; P=.368$; Figs 7 and 8 ).

Uptake of ${ }^{99 \mathrm{~m}} \mathrm{Tc}$-annexin $\mathrm{V}$ by transplanted allografts in group IV decreased in a similar fashion after treatment with cyclosporine and methylprednisolone. It reached baseline level on day 18 after transplantation, a pattern essentially the same as that seen in group III (data not shown).

\section{Discussion}

This study was designed to show the feasibility of using ${ }^{99 \mathrm{~m}} \mathrm{Tc}$-annexin $\mathrm{V}$ imaging to detect apoptosis during cardiac allograft rejection. The measurement of
Table III. Uptake of ${ }^{99 m} T c$-annexin V, measured as percentage of total body uptake, compared between grafts with the same histologic grade of rejection

\begin{tabular}{llc}
\hline Rejection $^{*}$ & Uptake $(\%)$ & $\mathrm{P} \dagger$ \\
\hline Grade $0(\mathrm{n}=31)$ & $0.42 \pm 0.17$ & \\
Grade $1(\mathrm{n}=5)$ & $0.83 \pm 0.31$ & .036 grade 0 \\
Grade 2 $(\mathrm{n}=10)$ & $1.43 \pm 0.40$ & .008 grade 1 \\
Grade 3 $(\mathrm{n}=14)$ & $2.40 \pm 0.53$ & $<.001$ grade 2 \\
\hline
\end{tabular}

Uptake percentages are expressed as mean \pm standard deviation. *Grafts that showed grade 0.5 rejection are not included in this table $(n=6)$. $\dagger$ Analyzed with 2-tailed, unpaired Student $t$ test, unequal variance.

intensity of uptake of ${ }^{99 \mathrm{~m}} \mathrm{Tc}$-annexin $\mathrm{V}$ leaves room for improvement. Uptake by the graft, indicated as percentage of total body uptake, does not seem to acceptably indicate the dramatic, visible changes seen in imaging of rejecting grafts. The kidneys of experimental and control animals all had marked uptake of ${ }^{99 \mathrm{~m}} \mathrm{Tc}$-annexin V. The renal uptake, however, did not preclude imaging of the cardiac grafts. The specific mechanism of renal binding is uncertain but may relate to the intrinsic lipid profile of the kidney, with high concentrations of phosphatidylserine in the cortex. ${ }^{21}$ Sensitivity and specificity of ${ }^{99 \mathrm{~m}} \mathrm{Tc}$-annexin $\mathrm{V}$ imaging are yet to be determined. A sharp definition of a positive scan result is required to calculate the fractions of false-positive and false-negative results in a larger, prospective study. Further refinement of the techniques used and welldesigned primate studies will be needed before use of ${ }^{99 \mathrm{~m}} \mathrm{Tc}$-annexin $\mathrm{V}$ imaging in human patients. 


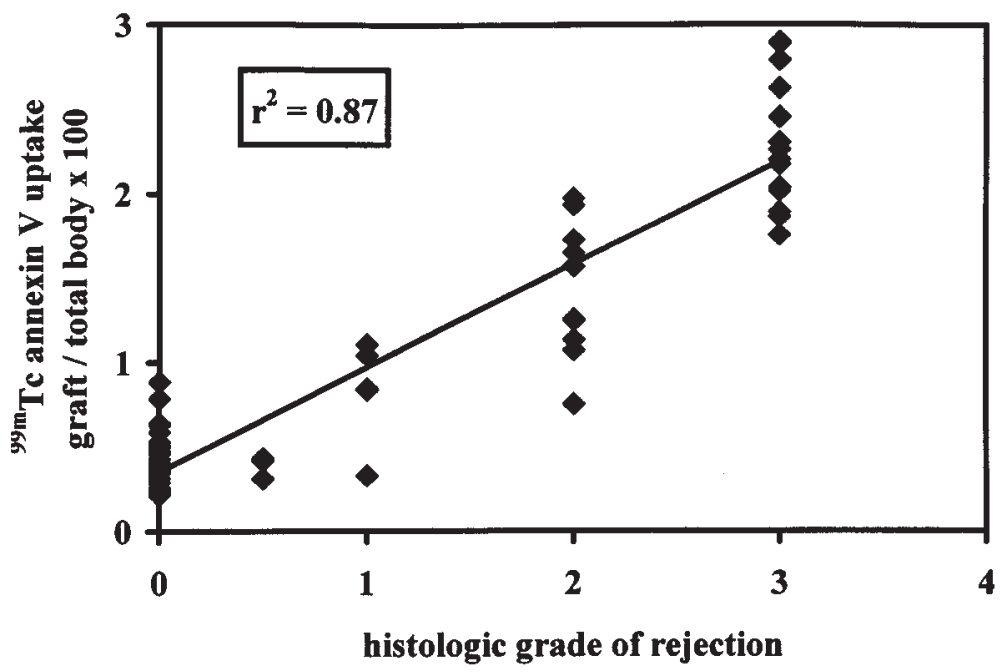

Fig 6. Correlation between histologic grade of acute rejection and uptake of ${ }^{99 m} \mathrm{Tc}-$ annexin $\mathrm{V}$, measured as percentage of total body uptake. Histologic grades are as shown in Fig 1. Each data point represents an individual cardiac graft.
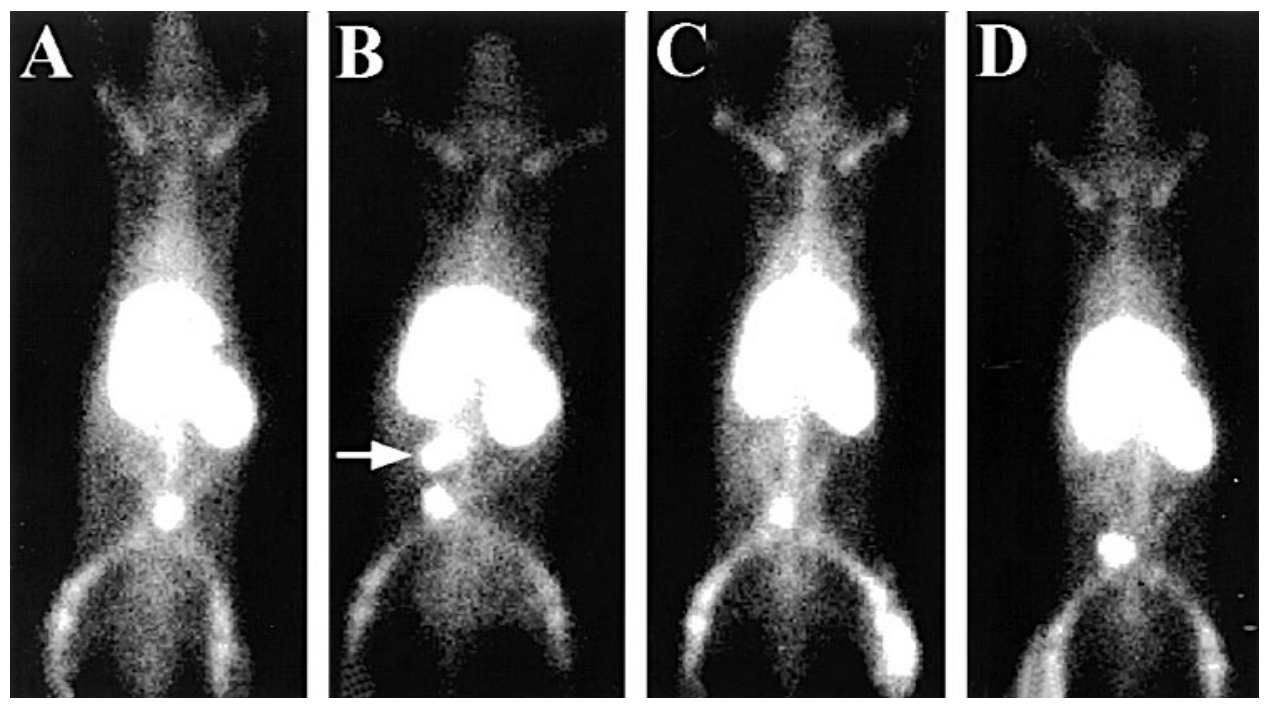

Fig 7. Uptake of ${ }^{99 \mathrm{~m}} \mathrm{Tc}$-annexin $\mathrm{V}$ in an allogeneic graft from group III. ACI recipients received cyclosporine treatment $(10 \mathrm{mg} / \mathrm{kg} / \mathrm{d})$ starting on day 4 after transplantation. A, Day 1 after transplantation, no treatment. B, Day 4 after transplantation, start of cyclosporine treatment. C, Day 11 after transplantation, after 7 days of cyclosporine treatment. D, Day 18 after transplantation, after 14 days of cyclosporine treatment, recovery from rejection. Panels show representative sequential images from 1 animal.

Clinical signs of rejection in cardiac allograft recipients can be subtle. ${ }^{22}$ This subtlety necessitates multiple surveillance endomyocardial biopsies. Endomyocardial biopsy is an invasive procedure that is uncomfortable for patients, costly, and associated with morbidity, such as tricuspid regurgitation. ${ }^{23}$ False-negative biopsy results could occur as a result of focal rejection, because endomyocardial biopsy assesses only random samples from the right ventricular septum. ${ }^{24}{ }^{99 \mathrm{~m}} \mathrm{Tc}-$ annexin $\mathrm{V}$ imaging allows noninvasive examination of the entire heart and can detect myocyte membrane changes in an early phase of cellular damage. This per- 


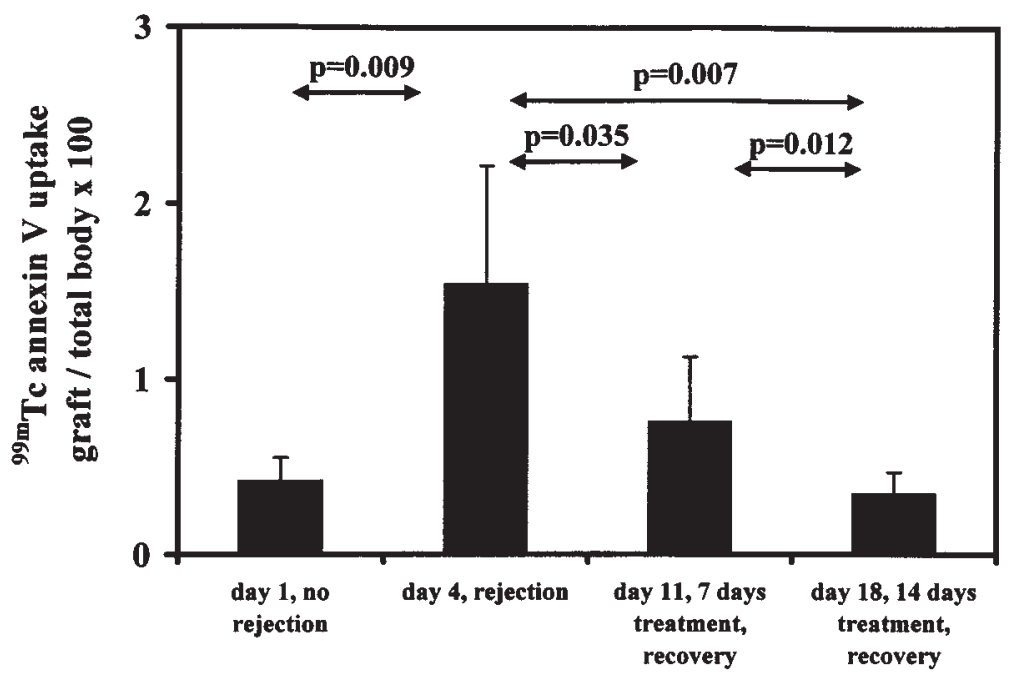

Fig 8. Uptake of ${ }^{99 \mathrm{~m}} \mathrm{Tc}$-annexin V in PVG allografts of group III, as a percentage of total body uptake. ACI recipients received cyclosporine treatment starting on day 4 after transplantation. Uptakes in allografts from group III were compared on days 1, 4, 11, and 18 after transplantation by a 2-tailed paired Student $t$ test with unequal vari-

mits early treatment, possibly even while cellular changes are still reversible.

Mechanisms of myocyte damage during cardiac allograft rejection range from apoptosis to necrosis. ${ }^{7,8}$ Apoptosis is a short-lived focal process of self-inflicted cell death. ${ }^{25}$ Loss of the normal asymmetry of the phospholipid bilayer during apoptosis has been shown to coincide with chromatin condensation before DNA cleavage by endonucleases. ${ }^{12}{ }^{99 \mathrm{~m}} \mathrm{Tc}$-annexin $\mathrm{V}$ detects apoptosis in an earlier stage than does TUNEL, which is specific for the later nuclear cleaving of chromatin. ${ }^{13}$ TUNEL, which requires processed myocardial tissue, was not abundant in histologic sections, even in rejecting allografts that showed a high uptake of ${ }^{99 \mathrm{~m}} \mathrm{Tc}-$ annexin V. The cell membrane remains impermeable during apoptosis and does not elicit an inflammatory response by exposure of endocellular substances and release of harmful enzymes to the surrounding tissues. $^{25}$ When necrosis occurs, however, the cellular membrane becomes permeable. ${ }^{25}{ }^{99 \mathrm{~m}} \mathrm{Tc}$-annexin $\mathrm{V}$ can also detect cells undergoing necrosis and bind to the intracellular phosphatidylserine when the integrity of the membrane is lost. ${ }^{99 \mathrm{~m}} \mathrm{Tc}-$ annexin $\mathrm{V}$ binds to myocytes during the entire spectrum of cellular death, from early in the apoptotic process to necrosis, and is therefore a more sensitive and more specific marker of rejection than is TUNEL.

${ }^{99 \mathrm{~m}} \mathrm{Tc}$-annexin $\mathrm{V}$ imaging is similar in concept to indium 111-labeled antimyosin antibody imaging. ${ }^{26}$ Antimyosin binds to myosin, which is exposed by necrotic myocytes. ${ }^{27}$ Noninvasive indium 111-labeled antimyosin antibody imaging requires between 24 and 48 hours after injection of radiolabeled antimyosin. 99m Tc-annexin $\mathrm{V}$ imaging can be performed 1 hour after injection of the radiopharmaceutical and can detect both apoptotic and necrotic cell deaths.

When rejection was successfully treated in our experiments, uptake of ${ }^{99 \mathrm{~m}} \mathrm{Tc}$-annexin $\mathrm{V}$ returned to baseline. Histologic examination still showed the presence of mononuclear cells, but without myocyte damage. TUNEL imaging confirmed that there were no myocytes undergoing apoptotic cell death. Clinically, lymphocytic infiltrates tend to resolve slowly in patients treated with cyclosporine, and it can take between 2 and 3 weeks after adequate treatment to obtain a clear biopsy specimen. ${ }^{22}$ This clinical observation is consistent with the histologic pattern seen in this study.

This study indicates that apoptosis occurs during acute cardiac allograft rejection and disappears after rejection has been successfully treated. ${ }^{99 \mathrm{~m}} \mathrm{Tc}$-annexin $\mathrm{V}$ imaging can detect apoptosis during cardiac allograft rejection. Uptake of ${ }^{99 \mathrm{~m}} \mathrm{Tc}$-annexin $\mathrm{V}$ correlates well with histologic grade of acute rejection. Intensity of uptake of ${ }^{99 \mathrm{~m}} \mathrm{Tc}$-annexin $\mathrm{V}$ could provide an indication of whether a patient needs further analysis and whether an endomyocardial biopsy is indicated. There is virtually no circulating blood pool of endogenous annexin $\mathrm{V}$ to compete with binding sites on the phosphatidylserine-expressing apoptotic cells or dilute injected radiolabeled annexin V. ${ }^{16}$ Because the phos- 
phoserine head group of phosphatidylserine has the same structure in all species and we used human annexin $\mathrm{V}$ in this study, ${ }^{99 \mathrm{~m}} \mathrm{Tc}$-annexin $\mathrm{V}$ promises to be applicable to human patients.

The results of this study provide the foundation for refinement of ${ }^{99 \mathrm{~m}} \mathrm{Tc}$-annexin $\mathrm{V}$ imaging in a nonhuman primate study. Clinically, this novel method of noninvasive diagnosis of cardiac allograft rejection could potentially eliminate the need for routine surveillance endomyocardial biopsy.

We thank Michael J. Abrams, MD, for kindly providing the HYNIC used in this study, Susan Kopiwoda for outstanding technical support during the nuclear imaging and analysis of the data, Grant Hoyt for excellent performance of the microsurgery, and Bonny Bell for processing of the histologic sections.

\section{REFERENCES}

1. Hutchinson IV. Cellular mechanisms of allograft rejection. Curr Opin Immunol 1991;3:722-8.

2. Duke RC. Apoptosis in cytotoxic T lymphocytes and their targets. Semin Immunol 1992;4:407-12.

3. Meehan SM, McCluskey RT, Pascual M, Preffer FI, Anderson P, Schlossman SF, et al. Cytotoxicity and apoptosis in human renal allografts: identification, distribution, and quantitation of cells with a cytotoxic granule protein GMP-17 (TIA-1) and cells with fragmented nuclear DNA. Lab Invest 1997;76:639-49.

4. Krams SM, Egawa H, Quinn MB, Villanueva JC, GarciaKennedy R, Martinez OM. Apoptosis as a mechanism of cell death in liver allograft rejection. Transplantation 1995;59:621-5.

5. Fayyazi A, Schlemminger R, Gieseler R, Peters JH, Radzun HJ. Apoptosis in the small intestinal allograft of the rat. Transplantation 1997;63:947-51.

6. Shaddy RE. Apoptosis in heart transplantation. Coron Artery Dis 1997;8:617-21.

7. Laguens RP, Meckert PM, Martino JS, Perrone S, Favaloro R. Identification of programmed cell death apoptosis in situ by means of specific labeling of nuclear DNA fragments in heart biopsy samples during acute rejection episodes. J Heart Lung Transplant 1996;15:911-8.

8. Bergese SD, Klenotic SM, Wakely ME, Sedmak DD, Orosz CG. Apoptosis in murine cardiac grafts. Transplantation 1997;63:3205.

9. Jollow KC, Sundstrom JB, Gravanis MB, Kanter K, Herskowitz A, Ansari AA. Apoptosis of mononuclear cell infiltrates in cardiac allograft biopsy specimens questions studies of biopsy-cultured cells. Transplantation 1997;63:1482-9.

10. Zwaal RF, Schroit AJ. Pathophysiologic implications of membrane phospholipid asymmetry in blood cells. Blood 1997;89: 1121-32.

11. Op DK. Lipid asymmetry in membranes. Annu Rev Biochem 1979;48:47-71.

12. Martin SJ, Reutelingsperger CP, McGahon AJ, Rader JA, van Schie RC, LaFace DM, et al. Early redistribution of plasma membrane phosphatidylserine is a general feature of apoptosis regardless of the initiating stimulus: inhibition by overexpression of Bcl-2 and Abl. J Exp Med 1995;182:1545-56.

13. Cohen GM, Sun XM, Snowden RT, Dinsdale D, Skilleter DN. Key morphological features of apoptosis may occur in the absence of internucleosomal DNA fragmentation. Biochem J 1992;286(Pt 2):331-4.

14. Gavrieli Y, Sherman Y, Ben-Sasson SA. Identification of programmed cell death in situ via specific labeling of nuclear DNA fragmentation. J Cell Biol 1992;119:493-501.

15. Koopman G, Reutelingsperger CP, Kuijten GA, Keehnen RM, Pals ST, van Oers MH. Annexin V for flow cytometric detection of phosphatidylserine expression on B cells undergoing apoptosis. Blood 1994;84:1415-20.

16. Stratton JR, Dewhurst TA, Kasina S, Reno JM, Cerqueira MD, Baskin DG, et al. Selective uptake of radiolabeled annexin V on acute porcine left atrial thrombi. Circulation 1995;92:3113-21.

17. Abrams MJ, Juweid M, tenKate CI, Schwartz DA, Hauser MM, Gaul FE, et al. Technetium-99m-human polyclonal IgG radiolabeled via the hydrazide nicotinamide derivative for imaging focal sites of infection in rats. J Nucl Med 1990;31:2022-8.

18. Ono K, Lindsey ES. Improved technique of heart transplantation in rats. J Thorac Cardiovasc Surg 1969;57:225-9.

19. Tait JF, Engelhardt S, Smith C, Fujikawa K. Prourokinase-annexin V chimeras: construction, expression, and characterization of recombinant proteins. J Biol Chem 1995;270:21594-9.

20. Blankenberg FG, Katsikis PD, Tait JF, Davis RE, Naumovski L, Ohtsuki $\mathrm{K}$, et al. In vivo detection and imaging of phosphatidylserine expression during programmed cell death. Proc Natl Acad Sci U S A 1998;95:6349-54.

21. Sterin-Speziale N, Kahane VL, Setton CP, Fernandez MC, Speziale EH. Compartmental study of rat renal phospholipid metabolism. Lipids 1992;27:10-4.

22. Billingham ME. Endomyocardial biopsy detection of acute rejection in cardiac allograft recipients. Heart Vessels Suppl 1985; 1:86-90.

23. Williams MJ, Lee MY, DiSalvo TG, Dec GW, Picard MH, Palacios IF, et al. Biopsy-induced flail tricuspid leaflet and tricuspid regurgitation following orthotopic cardiac transplantation. Am J Cardiol 1996;77:1339-44.

24. Zerbe TR, Arena V. Diagnostic reliability of endomyocardial biopsy for assessment of cardiac allograft rejection. Hum Pathol 1988; 19:1307-14.

25. Majno G, Joris I. Apoptosis, oncosis, and necrosis. An overview of cell death. Am J Pathol 1995;146:3-15.

26. Frist W, Yasuda T, Segall G, Khaw BA, Strauss HW, Gold H, et al. Noninvasive detection of human cardiac transplant rejection with indium-111 antimyosin (Fab) imaging. Circulation 1987;76: V81-5.

27. Scheutz A, Breuer M, Kemkes BM. Antimyosin antibodies in cardiac rejection. Ann Thorac Surg 1997;63:578-81.

\section{Discussion}

Dr Gregory M. Hirsch (Halifax, Nova Scotia, Canada). The concept of a method of assessing apoptosis in vivo is exciting. We have an interest in apoptosis measurements in chronic rejection, and I have some thoughts about these issues. Most of your measurements were done early after transplantation, until day 5 , at a time when there is a fair degree of acute inflammatory infiltrate. Inflammatory cell death can be confusing at these early times because it can cause a degree of DNA fragmentation and cause false-positive staining with TUNEL, which is the gold standard against which you are measuring the annexin V. When we 
measure apoptosis during a time of acute inflammation, we take the TUNEL result with a grain of salt and try to rely on at least some corroborative method, either transmission electron microscopic morphologic description of apoptotic cell death, which is fairly characteristic, or DNA laddering. You lose the in situ representation with DNA laddering, but at least you can show the actual internucleosomal fragmentation. Do you have data, or do you have plans to correlate this annexin $\mathrm{V}$ assessment with a more solid assessment, such as transmission electron microscopic examination or DNA laddering? I think that you are on slightly shaky ground early, when there is a fair bit of inflammation and there might just be nonspecific inflammatory cell death driving the apoptotic signal.

Further, do you have data or do you intend to correlate the annexin V standing with better benchmarks of apoptotic activity (positive control preparations)? For example, I might suggest gut lumen, which always has a degree of apoptosis in the complete absence of inflammation and would be a useful control preparation.

Dr Vriens. That last is a great suggestion, and your point is well taken. TUNEL staining indeed indicates DNA cleavage, which occurs at a later stage of apoptosis, and annexin V stains apoptotic nuclei at a much earlier stage. We definitely plan to try to correlate different studies for apoptosis with annexin $\mathrm{V}$ uptake. 